\title{
A MODEL FOR BUSINESS PERFORMANCE IMPROVEMENT: A CASE OF THE POSTAL COMPANY
}

\author{
Dragan LAZAREVIĆ(D) 1 , Momčilo DOBRODOLAC (D) ${ }^{*}$, \\ Libor ŠVADLENKA (iD) ${ }^{2}$, Bojan STANIVUKOVIĆ ${ }^{1}$ \\ ${ }^{1}$ Faculty of Transport and Traffic Engineering, University of Belgrade, Belgrade, Serbia \\ ${ }^{2}$ Faculty of Transport Engineering, University of Pardubice, Pardubice, Czech Republic
}

Received 24 July 2019; accepted 04 February 2020

\begin{abstract}
The aim of this paper is to propose a management model which would assess the state of the business and indicate the improvement points, as well as to demonstrate the applicability of the model in a case of the postal company. An A'BA model is proposed which represents a combined application of Analytic Hierarchy Process - AHP method as a multi-criteria decision making tool and theory of business areas. The research consists of two parts. To define the most important influencing factor on business performance, the experts are interviewed. A new concept is proposed and applied in the process of aggregating experts' assessments based on their mapping in a plane. This creates the appropriate surface, and the position of its centroid in relation to the Saaty's scale defines the final score of pairwise comparison - an indicator of the relationship between two elements that are compared. In the second part, additional experts from the determined area are involved to define an approach for detailed analysis of the most important factor. In this case, the approach included a survey of employees based on the specialized questionnaire. The guidelines for business performance improvement are obtained.
\end{abstract}

Keywords: business process, business performance, improvement, decision-making, postal company, management, experts' assessments aggregation, Saaty's scale in the plane.

JEL Classification: D29, L21, L32, L87, M11, M12.

\section{Introduction}

Systems for the distribution of goods, both at the national and international level, are very important for the appropriate business functioning and also for a normal life of citizens. A distribution system can be found as a great business segment of the company, or more often as a specialized independent company. This is usually a complex system with advanced fleet and numerous employees. Stochastic market requirements and also the internal effects, make the task to organize the business process very difficult. This may lead to the negative

${ }^{\star}$ Corresponding author. E-mail: m.dobrodolac@sf.bg.ac.rs 
consequences, affecting the level of business performance. To achieve a sustainable business, it is necessary to perform continuous monitoring and improvement of business processes and activities. The model proposed in this paper is a strategic approach to improve the business performance in distribution systems.

Organizing a business process involves decision-making. Decision making implies a selection of one out of two or more alternative actions. The question of choice arises because the company's resources are limited and can be employed in alternative ways. The main aim of this study is to propose a model and its application for getting directions for business performance improvement. Furthermore, the implementation of the proposed model should provide information about the most influential factors and business areas affecting the business performance in positive or negative sense. Additionally, it was demonstrated how the obtained most influential factor could be further analysed and by that achieved concrete improving directions. The A'BA, which is proposed and applied in this paper, is a hybrid method connecting a multiple criteria decision support method (in this study Analytic Hierarchy Process - AHP) to the business areas of business process. The idea for creating such a model resulted from the similar concept combining AHP and SWOT (A'WOT method), which can be found in the literature (Görener, 2012). In addition, as a contribution to the AHP method, a new approach for the aggregation of experts' assessments is proposed, based on the analysis of the centroid of the corresponding surface created in the plane based on the values of the experts' assessments. This paper presents a comparative overview of the results obtained in this new way and those obtained based on the approach recommended by the AHP method creators and other authors - by calculating the geometric mean of experts' assessments (Aczél \& Saaty, 1983; Saaty, 1989; Forman \& Peniwati, 1998; Ossadnik et al., 2016).

The research consists of two parts. At the beginning the experts are interviewed in order to define the influential factors on business performance, the importance of business areas and the importance of each factor inside them. These answers are the inputs for the first part of the proposed model which gives as a result the most important influencing factor at the global level (across all business areas). In the considered case, the results indicated the "Work-related attitudes and motivation of personnel" to be the most influential factor. Additional experts are involved in the group of experts and was contacted to define an approach for this factor further analysis. Accordingly, the survey using the Organizational Commitment Questionnaire (OCQ) was conducted in the second part of the research. There were 204 employees contacted, of which 160 was taken in the final data processing, with the final aim to get recommendations about the possible improvements. The applicability of the proposed model is proven in the case of the postal company from Serbia, which is one of the biggest distribution systems in the region of South-East Europe. It is well known that a reliable and efficient postal system has a significant impact on the economic development of each state, as well as on the quality of life of its citizens (Dobrodolac et al., 2016). In order the service to be as high quality as possible while using the limited resources in the optimal way, it is necessary to analyse the business process of each postal company. The model proposed in this paper could be used for this purpose. The organization of this study is as follows: in the second section, a review of the literature from the field and the basic principles of AHP are presented. In the next section, the proposed A'BA model is described. Then, the application 
of proposed model is demonstrated in the case of public postal operator in Serbia. Here it is also presented the methodology of survey using the Organizational commitment questionnaire and the results of its implementation. Based on the obtained results, the recommendations (activities) for business performance improvement are provided. Finally, the benefits that the proposed model could bring to the company in which it is applied are highlighted.

\section{Literature review}

As previously mentioned, the idea for the creation of A'BA model resulted from the combined application of SWOT (Strengths, Weaknesses, Opportunities and Threats) and AHP method. SWOT analysis is based on the collection and analysis of influencing factors on the observed entity and thus allows a detailed analysis about this entity (Kotler, 1988; Wheelen \& Hunger, 1995). Collected factors are grouped into four SWOT groups: strengths, weaknesses, opportunities and threats. Following the example of this, in the framework of the proposed model, the considered influencing factors are grouped into business areas. There is no limit in the number of these groups (business areas); however, it certainly depends on the specific case and type of the collected factors. To analyse the factors between themselves or business areas it is necessary to determine their relative importance, respectively. This can be achieved by pairwise comparison which is an element of widely applied and mathematically grounded technique so-called Analytic Hierarchy Process (AHP). AHP as a multi-criteria decision method defines a formal framework for decision making process, providing analysts a tool for complex problems modelling through hierarchical structure. As a result, there is a relationship between the pairs which are compared. The combination of AHP and theory of business areas makes a solution to determine the business area and factor to be improved in order to achieve higher business performance. Subjective preferences and expert knowledge can both be included in the same decision analysis. Besides forming the list of relevant factors, by using AHP pairwise comparison based on Saaty's comparison scale, it is possible to obtain their relative importance (Saaty, 1977). AHP method is characterized by the ability to identify and analyse inconsistencies. The analysts who determines the relationship between elements can be inconsistent. AHP method provides a solution to this problem by calculating the level of consistency (CR). For example, if there is a claim that $\mathrm{A}$ is much more important than B, B something more important than $\mathrm{C}$ and $\mathrm{C}$ is something more important than A; then inconsistency occurs and reduces the reliability of results (Forman, 1993). The consistency ratio less than 0.1 is satisfactory. If this value is higher than the defined limit, the evaluation procedure needs to be repeated (Görener, 2012; Borajee \& Yakchali, 2011; Görener et al., 2012). The relevance of the obtained results of the AHP method application depends largely on the aggregation of experts' assessments when comparing two elements. A well-known approach in the literature to find the final score of pairwise comparison is to calculate a geometric mean of the assessments of all the participating experts. Numerous authors have dealt with the analysis of the aggregation method of experts' assessments (Aczél \& Saaty, 1983; Saaty, 1989; Forman \& Peniwati, 1998; Cho et al., 2008; Huang et al., 2009; Ossadnik et al., 2016; Toth \& Vacik, 2018). Theory of the business areas is based on the segmentation of business processes and their characteristics according to their relatedness. A 
business area is determined by the set of corresponding business processes and its characteristics which belong to it. In the proposed model, the elements of the mentioned set represent the influencing factors on business performance. Multi criteria analysis methods individually, but also combined with SWOT and similar techniques, are frequently used approaches for solving decision-making problems or improvement in different areas of management and business. Speaking about the transportation science and systems of distribution, AHP method is used by Kim et al. (2013) in the process of competitivity improvement of Korea Parcel Service. Teichmann et al. (2014) in their paper applied multiple criteria analysis for optimization of the distribution system structure. The group of authors (Vieira et al., 2017) used the AHP method to create a framework for defining operations and its managing in distribution centers. In the field of logistics, a concept based on a fuzzy analytic hierarchy process was applied. Wang et al. (2016) applied a fuzzy AHP for forming approaches to support the selection of transport mode for military logistics, and similar approach was used for a decision-making tool in third-party logistics (3PL) provider selection (Bulgurcu \& Nakiboglu, 2018; Singh et al., 2018; Jovčić et al., 2019). Alkharabsheh et al. (2019) analysed passenger demand for the development of the urban transport system by an AHP model. Cyril et al. (2019) have developed a method based on AHP, could be used for performance evaluation and optimization of different public transport systems. A combined SWOT and AHP method is used by many authors. Wang et al. (2014) used the combined model for the purpose of the analysis of influential factors on the business and defining the appropriate business strategies in China Worldwide Express Mail Service. Dobrodolac et al. (2016) analysed how the universal postal service providers could improve their competitiveness. Here, besides SWOT and AHP, a geometrical approach is proposed for identification of improvement points. The combined method is also used by Shahba et al. (2017) in order to efficiently manage waste in the mines in Iran. They combined the implementation of SWOT, AHP and TOPSIS. Forming strategy for management of environment has been the aim of research of Cerlyawati et al. (2017). As a result of the applied methodology, the directions for rehabilitation of ecosystems are proposed. Similar issues were considered by Etongo et al. (2018) who assessed the forest management efficiency. Their findings support the activities related to sustainable development of rural areas and environmental protection. Gottfried et al. (2018) used an approach based on the combined method and its modifications for defining investment criteria in biogas. To define the strategy of business improvement, Abdel-Basset et al. (2018) proposed an approach based on the combined application of the AHP and SWOT analysis. Here, the AHP was applied in a neutrosophic environment and the applicability of the proposed methodology was tested in the case of Starbucks Company. A combined SWOT and AHP method was used for a forming sustainable development strategy for the Uzbekistan textile industry (Kim \& Park, 2019). A similar methodology has been implemented to define strategies and solve issues in the environmental (Solangi et al., 2019) and tourism (Liu et al., 2019; Kişi, 2019) area. 


\section{Proposal of the A'BA model and new concept of aggregation of expert's assessments}

\subsection{A'BA model}

Strategic management is a discipline that involves the implementation of different approaches in order to achieve the company's goals in the best way. In this paper, the A'BA model is proposed representing a combined application of AHP method as a multi-criteria decisionmaking tool and theory of business areas. The A'BA model can be described in six steps:

Step 1. Collecting the expert opinions about the factors which have the effect on the business performance;

Step 2. Defining the business areas (BA) based on the collected factors and factors assignment to each of them;

Step 3. Collecting the expert opinions on the importance of business areas and factors in these areas. Calculation of the importance of business areas and factors based on the collected data;

Step 4. Calculation of the global importance of the influencing factors on business performance;

Step 5. Conducting different analyses of the most important factor using an appropriate approach which depends on the type of the factor. This means a collection of expert opinions about the approaches for detailed analysis of the factor; then about the importance of the proposed approaches; based on the results determining an adequate approach for the given problem; application of the chosen approach and corresponding analysis;

Step 6. The alternatives and activities are evaluated based on the analysis from step 5. This allows to propose the recommendations for the business performance improvement.

In the first step, experts give their views on the factors affecting the business performance. Collection of this information is carried out via interviews or questionnaires. Based on the collected factors, a conclusion can be made about the business areas that can be defined. It is desirable that each business area includes at least two or more influencing factors. After the factors and business areas are defined, the experts should give the opinion on the importance of business areas, as well as the factors within them. The experts express their opinions on the basis of Saaty's comparison scale (Saaty, 1977). In order to determine the final assessments when comparing two elements in the AHP approach, i.e. the aggregation of experts' assessments, in addition to the traditional concept where a geometric mean should be calculated as a representative of their relationship, a new concept is proposed in this paper. It is based on the analysis of the centroid of the corresponding surface created in the plane based on the values of the experts' assessments. Analysis of the data includes the application of AHP method, which as a final result gives the degrees of importance of each business area and each factor within the area. The results enable the determination of the global degree of importance of all influential factors. In this way, the factors could be ranked by the importance at the level of all business areas, i.e. at the level of the entire business process. A detailed analysis of the most important factors and method for its improvement, is carried out in the way described in steps 5 and 6 . By implementing the proposed model, it is possible to determine the 
most important factor and recommendations for successful functioning. This is particularly important in the circumstances of the lack of time or resources for comprehensive changes because a direction about the best effect improvement point is obtained. Besides that, there is an assumption that better improvement effects in the particular field can be expected by focusing on just one factor. The proposed model should be implemented in constant iterations, in order to establish the continuous improvement of the different segments (areas) of business process.

\subsection{A new concept for aggregation of experts' assessments using the Saaty's scale in the plane - SSP}

In this paper, a new concept for aggregation of experts' assessments is proposed named the Saaty's Scale in the Plane - SSP. This concept implies a design of appropriate surface in accordance with the experts' assessments, as well as the corresponding surface analysis in order to determine the final assessment of two elements that are compared. The Saaty's scale is set in the plane, and in relation to it, the experts' assessments are mapped, thus forming the surface. The essence of the concept is to determine a position of the centroid of the formed surface. This position in relation to the Saaty's scale defines an aggregate value of experts' assessments. The procedure should be performed for each pairwise comparison.

The concept can be described in the following steps (when comparing two elements $A_{m}$ and $\left.A_{n}\right)$ :

Step 1. Two axes should be defined in the plane (Figure 1):

a) Axis 1. - Saaty's scale (on the vertical axis there are values representing the levels (assessments) of the Saaty's scale);

b) Axis 2. - Experts (the horizontal axis represents the experts, which means that the length of this axis depends on the number of interviewed persons (on Figure 1).

Step 2. Grouping of assessments - it implies that from the assembled experts' assessments in comparing the two elements $\left(A_{m}\right.$ and $\left.A_{n}\right)$, two sets of assessments are formed. The first set is formed by the assessments which gives a higher importance to the element $A_{m}$, while in the second set there are assessments which favour the other element $A_{n}$. If an assessment gives the same importance to both elements, this assessment is part of both sets.

Step 3. Mapping the assessments in the plane - In each of two previously formed sets, the assessments should be grouped according to their values and mapped in growing order relative to the Saaty's scale. The mapping procedure implies a design of a dot at the position that corresponds to the expert and their assessment. By connecting the formed dots using the shortest distance, the surface is formed for each of two previously defined sets (see Figure 1). The Axis 2 (Experts) delimits the elements that are compared $\left(A_{m}\right.$ and $\left.A_{n}\right)$, or in the same time, the corresponding surfaces of two sets.

Step 4. Determining the final score of the comparison - from the independent surfaces, which are the result of the previous step, the union or the final surface is formed. Centroid $(C)$ is determined for this formed surface. An analysis of the centroid position $(C)$ defines which element has a greater importance. The position of the centroid on the side of the corresponding element relative to the Axis 2 shows that this element has a greater importance comparing to the other element. By analysing the position of the centroid $(C)$ with respect 
to the Axis 1 (Saaty's scale), it is defined how much a particular element is more important than other. The final score $\left(F_{s A_{m} A_{n}}\right)$ of the comparison of two elements $A_{m}$ and $A_{n}$ is formed on the basis of Equation (1):

$$
F_{s A_{m} A_{n}}=1+r,
$$

where $r$ is the value on the Axis 1, determined by the position of the centroid relative to it. The value $r$ shows how much a certain element is more important than other; however, this value needs to be increased by 1 since the same importance of the elements being compared is evaluated exactly by 1 . If the centroid is located on the Axis $2(r=0)$ the elements have the same importance, or the final score of the comparison $F_{s A_{m} A_{n}}=1$.

When comparing this new concept of experts' assessments aggregation with the traditional one, the further examination will show that they give similar results. However, the main advantages of the proposed new concept relate to the visualization of the comparisons of two elements and the improvement of the possibilities within the sensitivity analysis since it is easy to analyse the impact of change in the surface area and the position of the centroid on the change in the final assessment of the comparison.

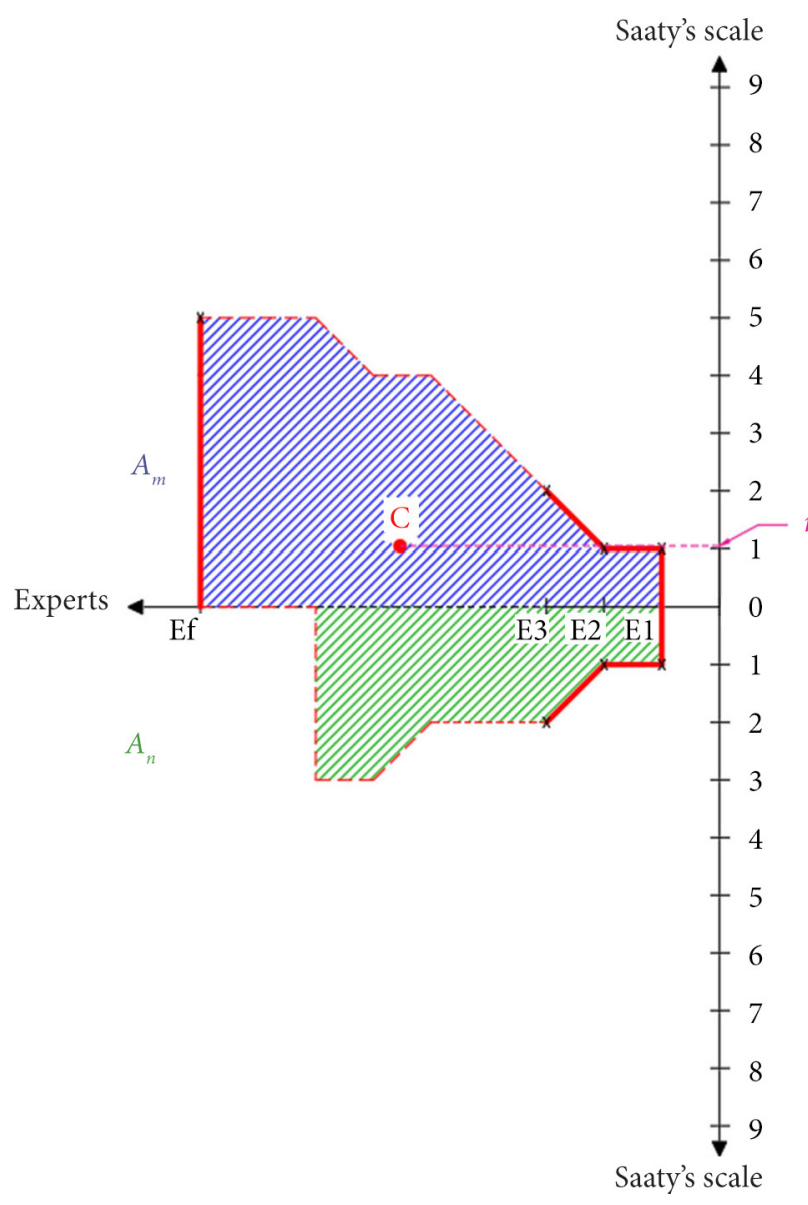

Figure 1. Aggregation of expert's assessments using a Saaty's scale in the plane - SSP 


\section{Application of the A'BA to improve a business performance of postal company}

\subsection{Influential factors and forming the $B A$}

To demonstrate the applicability of the proposed model, it was tested in the case of the postal company from Serbia. The factors are defined based on the interviews carried out with 12 experts. By the authors knowledge, the invited experts are some of the most eminent professionals in the Republic of Serbia considering the postal sector. The interviewees were university degree experts working in the analysed company, University of Belgrade and Regulatory Agency for Electronic Communications and Postal Services. All of them have years of experience and competencies in the analysed field of business. Seven of them were university degree experts from the analysed postal company:

- Two experts from the top management of the company;

- One expert from the sector involved in the organization of the technological process of postal items transfer (Sector for the postal network);

- One expert from the Development and strategy sector;

- Two experts from the Quality control sector;

- One expert from the Marketing sector.

Two experts are long-time researchers in the field of business process management and quality of the postal services, employed at the University of Belgrade. The other three experts are representatives of the Regulatory Agency for Electronic Communications and Postal Services. Their expertise relates to defining and developing regulations and strategies in the field of postal services, as well as to analyzing the postal services market.

Namely, based on all the expert opinions collected, the authors formed a set of influencing factors on business performance. The initial formed set, was returned to the experts for the verification, which resulted in the final set of influencing factors on business performance:

F1. Price, F2. Brand, F3. Extensive network and strong infrastructure, F4. Numerous workforce, F5. Own IT sector and information support, F6. Large vehicle fleet, F7. Modern equipment for the business process and investments in technology, F8. Service diversification, F9. Work-related attitudes and motivation of personnel, F10. The complexity of administration and low flexibility of the system, F11. The complexity of procedures for users, F12. Security of postal items, F13. The emergence of "bottlenecks" (lack of employees, vehicles and packaging), F14. Poor equipment of employees working outside, F15. Low efficiency level of resource usage, F16. Continuous training of employees, F17. Implementation of business process optimization models, F18. International regional cooperation, F19. Development the new services, F20. Improving and developing a long-term relationship with customers (through various forms of interaction), F21. Business information system, F22. Reduction of costs, F23. Development of modern strategic management models, F24. Marketing activities, F25. Flexibility of competition, F26. Stronger customer relationship management of competition, F27. The outflow of quality personnel, F28. Cooperation of private companies, F29. The large volumes of consignments, F30. The obligation of the public postal operator to cover the whole state territory, F31. Strong competition at management level. 
The authors further classify the collected factors into the business areas as shown in Table 1.

Table 1. BA matrix

\begin{tabular}{|l|l|}
\hline \multicolumn{1}{|c|}{ Business areas (BA) } & \multicolumn{1}{c|}{ Factors } \\
\hline BA1 - Transportation management system & F6, F17, F29, F30 \\
\hline BA2 - Human resource management & F4, F9, F16 \\
\hline BA3 - Physical and IT resource management & F3, F5, F7, F14, F21 \\
\hline BA4 - Market situation & F25, F26, F28 \\
\hline BA5 - Business policy & $\begin{array}{l}\text { F1, F2, F10, F13, F15, F18, F20, F22, F23, F24, } \\
\text { F27, F31 }\end{array}$ \\
\hline BA6 - Service management & F8, F11, F12, F19 \\
\hline
\end{tabular}

Transportation management system includes the business processes and activities relating to the management and organization of transport. This means the route planning, organization of the territory for delivery, assignment of transportation resources, development and application of optimization models for solving the transportation demands, etc. The postal company, as a national leader, base its business on the economies of scale, i.e. large volumes of consignments (F29). However, this entails a significant risk related to the security of items, meeting deadlines, organizing issues, etc. The fact that postal company has an obligation to cover the whole national territory with the universal postal service may lead to the problems in certain cases. In fact, it is unprofitable to operate at significant part of the territory; however, regardless of this, the company must reserve its resources in those areas because of the state regulations (F30). In order to successfully respond to all requests and effectively realize services, the postal company owns a large, diverse and modernized fleet of over 1,700 vehicles (F6). Additionally, application of appropriate optimization models (F17), it is possible to better organize the business activities in the system. This would result in numerous benefits, such as time and cost savings, efficient use of resources and etc.

Human resource management deals with all issues and management activities concerning the employees in the system. There is a direct relationship between employees and the performance of business processes, and thus the quality of service for the end user. The company has a large personnel potential, with around 15,000 employees (F4). Workrelated attitudes and motivation of personnel factor is proposed by most of the experts (F9). Its importance is confirmed by the research carried out by Dobrodolac et al. (2014) in the same company, where the majority of examined employees expressed a dissatisfaction related to many areas of business, such as process organization, interpersonal relations, work commitment, etc. The improvement of business process requires a constant education of employees in many segments (F16). For example, executing the standard business activities and particularly the implementation of new technologies require their understanding by the employees, which can be achieved only by training programs. Accordingly, it is necessary to conduct monitoring, education and training of employees, as well as to perform the activities which will motivate them. For each kind of activity, it is necessary to adhere to the principle of continuous implementation. 
Any system that deals with a certain vision of distribution of goods use the appropriate technical and infrastructural resources to successfully performed business activities. The fleet, means of mechanization for processing and handling of shipments, advanced automation systems, as well as the modern IT systems and equipment, are resources that should be invest, maintain, as well as properly and efficiently used. Having in mind the obligation imposed by the state authorities to cover the whole territory of the country by its services, the postal company has an extensive network and strong infrastructure (F3). Therefore, there is a possibility to offer services to all citizens which gives the public postal operators a significant strength. Additionally, the company has modern equipment and mechanization to perform the business process, such as machines for automatic processing and sorting of postal items, mechanization for transport and manipulative activities, computer equipment, teller equipment, various portable terminals, etc. Due to economies of scale, the company is in position to continually modernize its equipment and technology (F7). The company totally modernized its three main postal hubs in the year 2014. The new capacities and infrastructure could be offered even to the third parties. The new technologies could improve the business process and quality of existing services or lead to the design of new services. When it comes to outside business activities, the company mainly has the necessary equipment (various portable terminals); however, their number is not sufficient sometimes (F14). In these circumstances it is very complicated to successfully organize the business process. One of the most important projects of the company is the implementation of a highly sophisticated, comprehensive steel technology and information system, which enables a smooth and simplified business process through software application support, as well as storage and flow of information (F21). In addition, the company possess its own IT sector and information support which enables the company to offer various e-services, develop and maintain different software solutions (F5).

A performance of market-oriented system is exposed to everyday external influences. These effects stem from the competition, existing and potential customers, certain changes in the market, cooperation with other systems, etc. Each of these impacts could evoke a strong challenge for the business system; therefore, it is of a great importance to track the market developments in the considered field. One of the most prominent features of competition on the market is flexibility (F25). Namely, the private postal operators are relatively small companies which provides them a flexibility in business. This means they are prepared for various corrections in performing postal services and variety of compromises with customers. Such systems quickly and efficiently solve a number of non-standard business challenges. To strengthen its position in the market, due to the flexibility they have, competing companies easier implement the techniques of customer relationship management (F26). This means they are in position to have closer relations with customers, better possibilities of negotiation, etc. To achieve better market results, the private companies easier make agreements about cooperation between them (F28), resulting in cost reduction, better marketing campaigns, etc.

Business policy includes a number of business processes and activities related to the manner of functioning of the company, the price and cost policies, as well as other 
procedures that can be integrated into a set of strategic approaches to the smooth conduct of the business process. The company has an ability to offer lower prices compared to the competition (F1). The reasons lie in the following facts: business is based on the economies of scale; integrated services generate additional income without increasing the costs of business processes; certain monopoly brings additional income, however the postal company is legally obliged on financial and territorial availability which can increase the costs. Development and application of different strategic management models, as well as the optimization of business process, can significantly contribute to the reduction of total costs (F22). In the contemporary business, characterized by a competitive market, the development and application of modern strategic models has become a necessity (F23). Due to the numerous possible rationalizations these models can contribute to improving the efficiency, quality or performance of business. There are vulnerable segments in the system that need attention. Administrative procedures often negatively affect the performance of business process, due to the time delays and rigidities in certain procedures. Since the postal company is one the largest logistic systems in the country with 1507 branches, 17 regional sorting centres, 1508 vehicles and around 15000 employees, the complexity of administration and centralized decision-making do not allow quick changes based on the individual expectations of customers (F10). As can be inferred, the postal company has a developed infrastructure across the country. There are the objects which space is not efficiently used (F15). The situation is similar with equipment, employees or vehicles which could be better used. Also, a significant problem is a utilization of the cargo space of vehicles since they often perform transport operations with empty space left. In the operational part at certain moments, while performing the business process, "the bottlenecks" can occur which represents a special challenge and problem for the organizers of business activities (F13). A lack of couriers, vehicles or packaging, at some moment, is the most common problem of this kind. In the international postal flows, primarily due to the development of e-commerce, there was a significant increase in the volumes of postal items. Good cooperation among postal operators, primarily in the region, can contribution business performance (F18). On the other hand, there is a need and possibility to improve and develop a long-term relationship with customers (F20) through various types of interaction, such as forums, social networks for sharing experiences, 24/7 customer support centre, etc. The analysed postal company is the most famous company in the field providing postal services for more than 170 years (F2). This is maybe one of the reasons why citizens have a strong confidence in it. In addition, different marketing activities can be used to strengthen the market position (F24). One of the more recent emergent problems is related to the outflow of quality personnel (F27). Due to the lack of good conditions and motivation, there are cases where high-quality employees leave the company. The problem is increased by the fact that they generally find a new job at the competition. In this way the competition is strengthened and is not a rare case that their strong management personnel is made of the former employees of the postal company (F31).

Service management is a business area that deals with the analysis of existing service portfolio, their improvement and development of new services, as well as the issues concerning 
security of the postal items. The postal company offers the broadest portfolio of postal services in the country (F8). However, some of the procedures for service demand are quite complex, such as the procedure for express mail service ordering via Call Centre where the customers should provide a huge amount of data regarding the sender, addressee and shipment each time they call (F11). Security of postal items have an important impact on the service performance (F12). In a huge business system, such it is the postal company, a large number of postal items containing certain value circulate on a daily basis. Accordingly, the loss, damage or theft is possible to record. There are very diverse requirements on the postal market in terms of categories of items that are transferred, the special treatment of consignments, different timelines (usually the time of receipt and delivery), etc. As noted, the postal company has a developed network, infrastructure and numerous employees. On this basis, it can be concluded that there is a great potential for the development of new services (F19).

\subsection{Determining the relative importance between the BA groups}

The relationship between BA groups is determined based on pairwise comparison performed by interviewed experts. The aggregate evaluations assigned by them for each BA pair is shown in Table 2. Values outside brackets are aggregated using the geometric mean (GM) method, while the values in brackets are the result of aggregation using the concept proposed in this paper - Saaty's scale in the plane (SSP).

Table 2. Pairwise comparisons of BA groups

\begin{tabular}{|l|c|c|c|c|c|c|}
\hline $\begin{array}{c}\text { BA } \\
\text { groups }\end{array}$ & $\begin{array}{c}\text { BA1 } \\
\text { GM(SSP) }\end{array}$ & $\begin{array}{c}\text { BA2 } \\
\text { GM(SSP) }\end{array}$ & $\begin{array}{c}\text { BA3 } \\
\text { GM(SSP })\end{array}$ & $\begin{array}{c}\text { BA4 } \\
\text { GM(SSP })\end{array}$ & $\begin{array}{c}\text { BA5 } \\
\text { GM(SSP) }\end{array}$ & $\begin{array}{c}\text { BA6 } \\
\text { GM(SSP) }\end{array}$ \\
\hline BA1 & 1 & $1.070(1.163)$ & $1.189(1.273)$ & $1.303(1.426)$ & $1.381(1.580)$ & $1.428(1.607)$ \\
\hline BA2 & $0.935(0.860)$ & 1 & $1.134(1.252)$ & $1.513(1.743)$ & $1.303(1.456)$ & $1.348(1.518)$ \\
\hline BA3 & $0.841(0.786)$ & $0.882(0.799)$ & 1 & $1.096(1.147)$ & $1.122(1.190)$ & $1.059(1.091)$ \\
\hline BA4 & $0.767(0.701)$ & $0.661(0.574)$ & $0.913(0.872)$ & 1 & $0.813(0.750)$ & $0.833(0.746)$ \\
\hline BA5 & $0.724(0.633)$ & $0.767(0.687)$ & $0.891(0.840)$ & $1.230(1.333)$ & 1 & $0.841(0.777)$ \\
\hline BA6 & $0.700(0.622)$ & $0.742(0.659)$ & $0.944(0.917)$ & $1.201(1.341)$ & $1.189(1.286)$ & 1 \\
\hline
\end{tabular}

Based on the proposed approach and the appropriate calculations, the results shown in Table 9 (the second column) is obtained. Consistency ratio in this case is $\mathrm{CR}_{\mathrm{GM}}=0.002157$ $\left(\mathrm{CR}_{\mathrm{SSP}}=0.004443\right)$, which is under the limit of 0.1 , indicating the fulfilment of consistency criterion. The results indicate that the most important business area is Transportation management system - BA 1 (0.200963 (GM); 0.216153 (SSP)). Further, the importance of factors inside each business area is examined.

In the Figures 2 and 3, the results of the application of the SSP approach - the determination of the value of $r$, are presented. For calculation and visualization purposes, the Autodesk AutoCAD 2018 software was used.

In accordance with the defined position of the centroid of the formed surface, based on the Equation 1, a final assessment of the comparison of the elements B1 and B2 is $F_{s B_{1} B_{2}}=1.163$. 


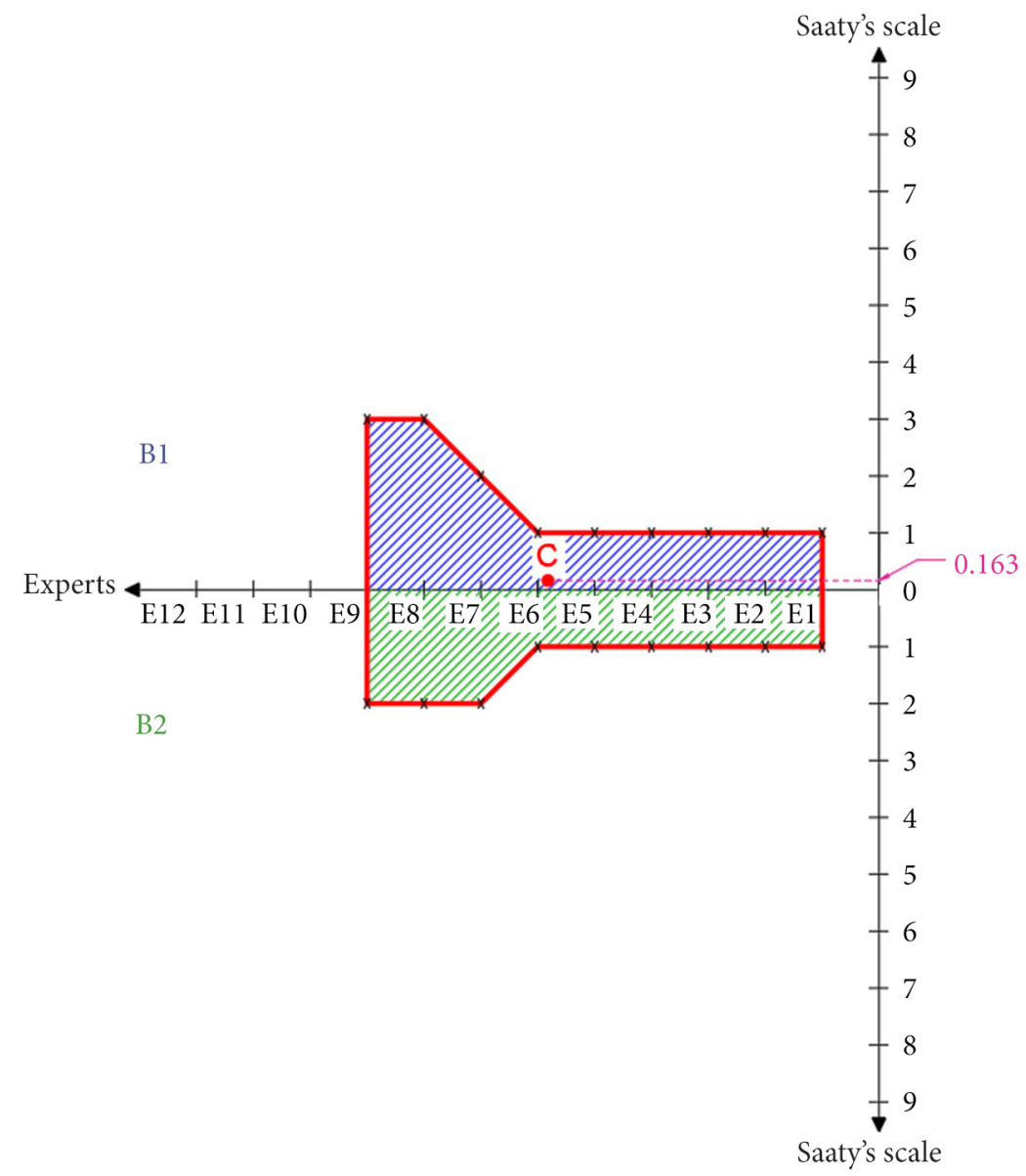

Figure 2. Aggregation of experts' assessments using the SSP for groups B1 and B2

Figure 3 shows only the resulting segments of the comparison of the remaining groups. According to the same principle, the proposed concept was applied to the aggregation of experts' assessments when comparing factors within business areas.

\subsection{Determining the importance of factors in the group Transportation management system - BA 1}

The group BA 1 includes four factors and their importance is measured by using expert opinions and the AHP method. It is obtained the following comparison matrix of BA1 group as shown in Table 3. By implementing the principles of AHP and the appropriate calculations, the relative importance between factors in BA 1 group is found (see the fourth column in Table 9). Consistency ratio in this case is $\mathrm{CR}_{\mathrm{GM}}=0.008445\left(\mathrm{CR}_{\mathrm{SSP}}=0.021212\right)$, on the basis of which can be concluded that it is satisfactory. The final results of comparison show that 


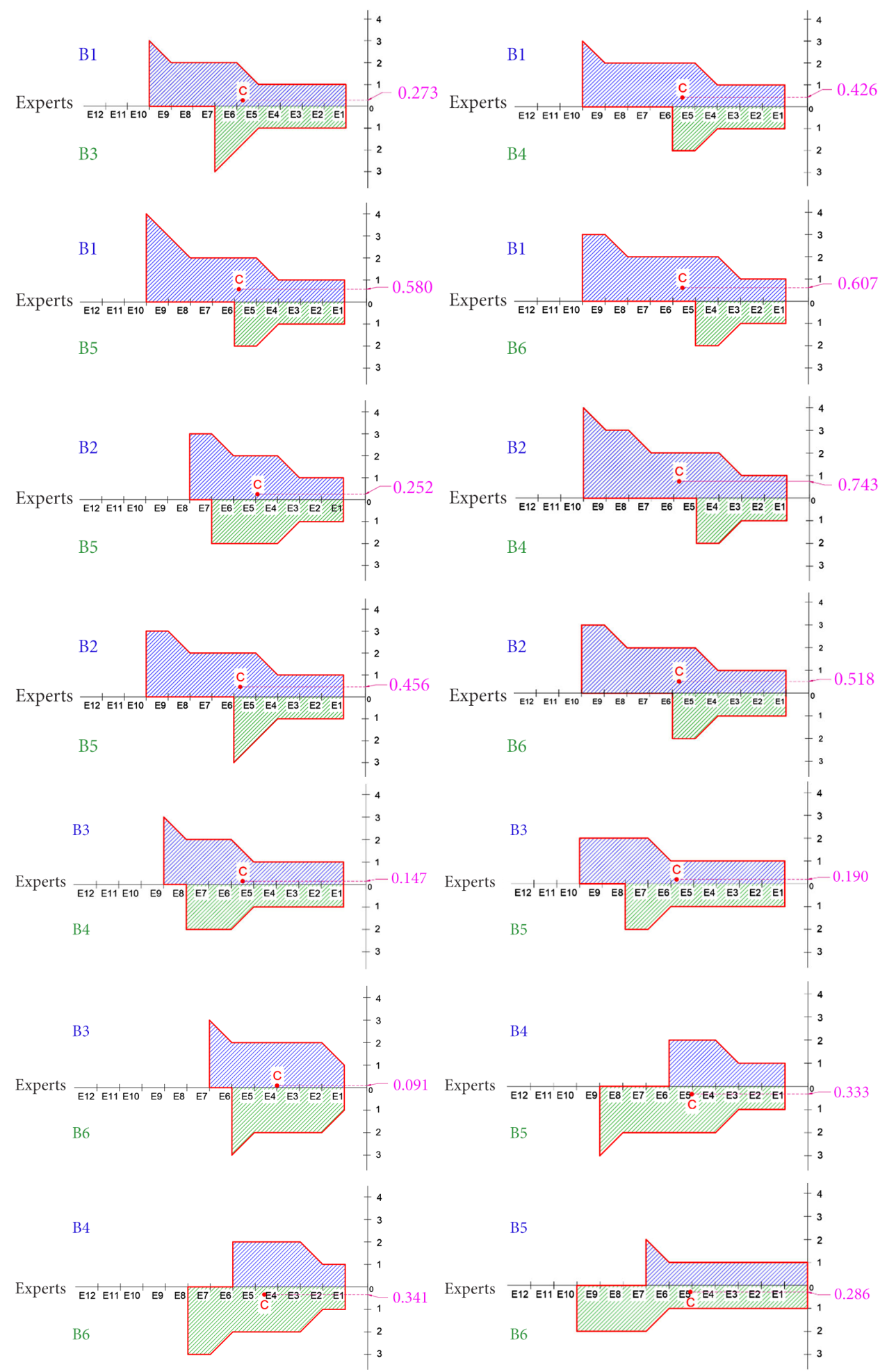

Figure 3. Aggregation of experts' assessments for all groups using the SSP 
the factor Implementation of optimization models has the highest impact in the business area - Transportation management system.

Table 3. Pairwise comparisons of factors in BA 1 group

\begin{tabular}{|c|c|c|c|c|}
\hline Factors & F6 GM(SSP) & F17 GM(SSP) & F29 GM(SSP) & F30 GM(SSP) \\
\hline F6 & 1 & $0.976(1.0218)$ & $0.935(0.889)$ & $0.861(0.806)$ \\
\hline F17 & $1.024(0.979)$ & 1 & $1.161(1.283)$ & $1.260(1.433)$ \\
\hline F29 & $1.070(1.128)$ & $0.861(0.780)$ & 1 & $0.742(0.659)$ \\
\hline F30 & $1.161(1.240)$ & $0.794(0.698)$ & $1.348(1.519)$ & 1 \\
\hline
\end{tabular}

\subsection{Determining the importance of factors in the group Human resource management - BA 2}

The group BA 2 includes three factors. The comparison matrix of BA 2 group as shown in Table 4 is obtained. Based on the proposed approach and the appropriate calculations, there are the results shown in Table 9 (the fourth column). Consistency ratio in this case is $\mathrm{CR}_{\mathrm{GM}}=$ $0.000003\left(\mathrm{CR}_{\mathrm{SSP}}=0.003667\right)$, which brings to the conclusion that it is satisfactory. The final results of comparison show that factor Work-related attitudes and motivation of personnel has the highest impact in the business area - Human resource management.

Table 4. Pairwise comparisons of factors in BA 2 group

\begin{tabular}{|c|c|c|c|}
\hline Factors & F4 GM(SSP) & F9 GM(SSP) & F16 GM(SSP) \\
\hline F4 & 1 & $0.569(0.547)$ & $0.749(0.677)$ \\
\hline F9 & $1.757(1.829)$ & 1 & $1.303(1.493)$ \\
\hline F16 & $1.335(1.476)$ & $0.767(0.670)$ & 1 \\
\hline
\end{tabular}

\subsection{Determining the importance of factors in the group Physical and IT resource management - BA 3}

The group BA 3 includes five factors and the following comparison matrix for this group is shown in Table 5. By implementing the proposed methodology, the relative importance between factors in BA 3 group is obtained (see the fourth column in Table 9). Consistency ratio in this case is $\mathrm{CR}_{\mathrm{GM}}=0.001854\left(\mathrm{CR}_{\mathrm{SSP}}=0.001770\right)$, indicating the satisfactory result. The final results of comparison show that factor Extensive network and strong infrastructure has the highest impact in the business area - Physical and IT resource management.

Table 5. Pairwise comparisons of factors in BA 3 group

\begin{tabular}{|c|c|c|c|c|c|}
\hline Factors & F3 GM(SSP) & F5 GM(SSP) & F7 GM(SSP) & F14 GM(SSP) & F21 GM(SSP) \\
\hline F3 & 1 & $1.096(1.147)$ & $1.272(1.430)$ & $1.619(1.793)$ & $1.757(1.889)$ \\
\hline F5 & $0.913(0.872)$ & 1 & $1.034(1.054)$ & $1.122(1.182)$ & $1.348(1.518)$ \\
\hline F7 & $0.786(0.699)$ & $0.967(0.948)$ & 1 & $1.189(1.25)$ & $1.150(1.225)$ \\
\hline F14 & $0.618(0.558)$ & $0.891(0.846)$ & $0.841(0.8)$ & 1 & $1.059(1.091)$ \\
\hline F21 & $0.569(0.529)$ & $0.742(0.658)$ & $0.870(0.816)$ & $0.944(0.917)$ & 1 \\
\hline
\end{tabular}




\subsection{Determining the importance of factors in the group Market situation - BA 4}

The group BA 4 includes three factors. The following comparison matrix of BA 4 group as shown in Table 6 is obtained. Based on the proposed approach and the appropriate calculations, there are the results shown in Table 9 (the fourth column). Consistency ratio in this case is $\mathrm{CR}_{\mathrm{GM}}=0.013586\left(\mathrm{CR}_{\mathrm{SSP}}=0.028706\right)$, which is satisfactory. The final results of comparison show that factor Flexibility of competition has the highest impact in the business area - Market situation.

Table 6. Pairwise comparisons of factors in BA 4 group

\begin{tabular}{|c|c|c|c|}
\hline Factors & F25 GM(SSP) & F26 GM(SSP) & F28 GM(SSP) \\
\hline F25 & 1 & $1.161(1.240)$ & $0.944(0.917)$ \\
\hline F26 & $0.861(0.806)$ & 1 & $1.161(1.240)$ \\
\hline F28 & $1.059(1.091)$ & $0.861(0.806)$ & 1 \\
\hline
\end{tabular}

\subsection{Determining the importance of factors in the group Business policy - BA 5}

The group BA 5 includes twelve factors and corresponding comparison matrix is shown in Table 7.

Table 7. Pairwise comparisons of factors in BA 5 group

\begin{tabular}{|c|c|c|c|c|c|c|c|c|c|c|c|c|}
\hline $\begin{array}{l}\text { Fac- } \\
\text { tors }\end{array}$ & $\begin{array}{c}\mathrm{F} 1 \mathrm{GM} \\
(\mathrm{SSP})\end{array} \mid$ & $\begin{array}{c}\text { F2 GM } \\
\text { (SSP) }\end{array} \mid$ & $\begin{array}{c}\text { F10 } \\
\text { GM } \\
\text { (SSP) }\end{array}$ & $\begin{array}{c}\text { F13 } \\
\text { GM } \\
\text { (SSP) } \\
\end{array}$ & $\begin{array}{c}\text { F15 } \\
\text { GM } \\
\text { (SSP) }\end{array}$ & $\begin{array}{c}\text { F18 } \\
\text { GM } \\
\text { (SSP) }\end{array}$ & $\begin{array}{c}\text { F20 } \\
\text { GM } \\
\text { (SSP) }\end{array}$ & $\begin{array}{c}\text { F22 } \\
\text { GM } \\
\text { (SSP) }\end{array}$ & $\begin{array}{c}\text { F23 } \\
\text { GM } \\
\text { (SSP) } \\
\end{array}$ & $\begin{array}{c}\text { F24 } \\
\text { GM } \\
\text { (SSP) }\end{array}$ & $\begin{array}{c}\text { F27 } \\
\text { GM } \\
\text { (SSP) } \\
\end{array}$ & $\begin{array}{c}\text { F31 } \\
\text { GM } \\
\text { (SSP) }\end{array}$ \\
\hline $\mathrm{F} 1$ & 1 & & $\begin{array}{c}1.201 \\
(1.341)\end{array}$ & & $\begin{array}{c}1.150 \\
(1.306)\end{array}$ & $\begin{array}{c}1.348 \\
(1.519) \\
\end{array}$ & $\begin{array}{c}1.603 \\
(1.826) \\
\end{array}$ & & $\begin{array}{l}0.944 \\
(0.923)\end{array}$ & & $\begin{array}{c}1.348 \\
(1.519) \\
\end{array}$ & $\begin{array}{c}1.896 \\
(2.058)\end{array}$ \\
\hline F2 & & 1 & $(0.592)$ & $\begin{array}{c}0.569 \\
(0.511) \\
\end{array}$ & & & $\begin{array}{c}0.833 \\
(0.746)\end{array}$ & & & & & $\begin{array}{c}1.161 \\
(1.240)\end{array}$ \\
\hline F10 & & $\begin{array}{c}1.477 \\
(1.688)\end{array}$ & 1 & $\begin{array}{l}0.833 \\
(0.746)\end{array}$ & $\begin{array}{c}0.841 \\
(0.781) \\
\end{array}$ & $\begin{array}{c}1.303 \\
(1.426)\end{array}$ & $\begin{array}{c}1.381 \\
(1.580)\end{array}$ & & & & $\begin{array}{c}1.161 \\
(1.240)\end{array}$ & $\begin{array}{c}1.757 \\
(1.922) \\
\end{array}$ \\
\hline F13 & \begin{tabular}{|c|}
0.833 \\
$(0.727)$ \\
\end{tabular} & $\begin{array}{l}57 \\
55) \\
\end{array}$ & $\begin{array}{c}1.201 \\
(1.341) \\
\end{array}$ & 1 & \begin{tabular}{|c|}
1.161 \\
$(1.240)$ \\
\end{tabular} & & $\begin{array}{c}1.565 \\
(1.773) \\
\end{array}$ & & & & & $\begin{array}{c}1.698 \\
(1.857) \\
\end{array}$ \\
\hline F15 & & & $\begin{array}{c}1.189 \\
(1.280) \\
\end{array}$ & & 1 & $\begin{array}{c}1.260 \\
(1.381)\end{array}$ & & & & & $\begin{array}{c}1.060 \\
(1.095) \\
\end{array}$ & $\begin{array}{c}1.428 \\
(1.608) \\
\end{array}$ \\
\hline F18 & \begin{tabular}{|c|}
0.742 \\
$(0.659)$ \\
\end{tabular} & $\begin{array}{c}1.272 \\
(1.430) \\
\end{array}$ & $\begin{array}{c}0.767 \\
(0.701)\end{array}$ & $\begin{array}{c}0.742 \\
(0.659) \\
\end{array}$ & \begin{tabular}{|c|}
0.794 \\
$(0.724)$ \\
\end{tabular} & 1 & $\begin{array}{c}1.060 \\
(1.091)\end{array}$ & & \begin{tabular}{|c|}
0.786 \\
$(0.699)$ \\
\end{tabular} & & $\begin{array}{c}0.861 \\
(0.806) \\
\end{array}$ & $\begin{array}{c}1.348 \\
(1.519)\end{array}$ \\
\hline F20 & & & & $\begin{array}{c}0.639 \\
(0.564) \\
\end{array}$ & $\begin{array}{c}0.742 \\
(0.659) \\
\end{array}$ & $\begin{array}{c}0.944 \\
(0.917)\end{array}$ & 1 & & & $\begin{array}{c}0.742 \\
(0.659) \\
\end{array}$ & $\begin{array}{c}0.742 \\
(0.659)\end{array}$ & $\begin{array}{c}1.034 \\
(1.054) \\
\end{array}$ \\
\hline F22 & $\begin{array}{c}0.861 \\
(0.731)\end{array}$ & $\begin{array}{c}1.394 \\
(1.603)\end{array}$ & $\begin{array}{c}0.891 \\
(0.840)\end{array}$ & $\begin{array}{c}0.735 \\
(0.626) \\
\end{array}$ & $\begin{array}{c}0.891 \\
(0.846) \\
\end{array}$ & $\begin{array}{c}1.230 \\
(1.370)\end{array}$ & $\begin{array}{c}1.230 \\
(1.333)\end{array}$ & 1 & $\begin{array}{c}0.786 \\
(0.699)\end{array}$ & $\begin{array}{c}1.161 \\
(1.240)\end{array}$ & $\begin{array}{c}1.230 \\
(1.333)\end{array}$ & $\begin{array}{c}1.303 \\
(1.426) \\
\end{array}$ \\
\hline F23 & $\begin{array}{c}1.060 \\
(1.083)\end{array}$ & $\begin{array}{c}1.757 \\
(1.973)\end{array}$ & $\begin{array}{c}1.161 \\
(1.283)\end{array}$ & $\begin{array}{c}0.967 \\
(0.948) \\
\end{array}$ & $\begin{array}{c}0.976 \\
(0.963) \\
\end{array}$ & $\begin{array}{c}1.272 \\
(1.430)\end{array}$ & $\begin{array}{c}1.034 \\
(1.109)\end{array}$ & (1.43 & 1 & $\begin{array}{c}1.161 \\
(1.240)\end{array}$ & $\begin{array}{c}1.230 \\
(1.333)\end{array}$ & $\begin{array}{c}1.972 \\
(2.078) \\
\end{array}$ \\
\hline F24 & $\begin{array}{c}0.684 \\
(0.600)\end{array}$ & $\begin{array}{c}1.161 \\
(1.283)\end{array}$ & $\begin{array}{c}0.861 \\
(0.806)\end{array}$ & $\begin{array}{c}0.742 \\
(0.659) \\
\end{array}$ & $\begin{array}{c}0.912 \\
(0.872) \\
\end{array}$ & $\begin{array}{c}0.967 \\
(0.949)\end{array}$ & $\begin{array}{c}1.348 \\
(1.519)\end{array}$ & $\begin{array}{c}0.861 \\
(0.806)\end{array}$ & $\begin{array}{c}0.861 \\
(0.806)\end{array}$ & 1 & $\begin{array}{c}0.742 \\
(0.659)\end{array}$ & $\begin{array}{c}1.161 \\
(1.240)\end{array}$ \\
\hline F27 & $\begin{array}{c}0.742 \\
(0.659)\end{array}$ & $\begin{array}{c}1.172 \\
(1.380)\end{array}$ & $\begin{array}{c}0.861 \\
(0.806)\end{array}$ & $\begin{array}{c}0.786 \\
(0.699) \\
\end{array}$ & $\begin{array}{c}0.944 \\
(0.913) \\
\end{array}$ & $\begin{array}{c}1.161 \\
(1.240)\end{array}$ & $\begin{array}{c}1.348 \\
(1.519)\end{array}$ & $\begin{array}{c}0.813 \\
(0.750)\end{array}$ & $\begin{array}{c}0.813 \\
(0.750)\end{array}$ & $\begin{array}{c}1.348 \\
(1.519) \\
\end{array}$ & 1 & $\begin{array}{c}1.817 \\
(1.953) \\
\end{array}$ \\
\hline 31 & $\begin{array}{c}0.527 \\
(0.486)\end{array}$ & $\begin{array}{c}0.861 \\
(0.806)\end{array}$ & $\begin{array}{c}0.569 \\
(0.520)\end{array}$ & $\begin{array}{c}0.589 \\
(0.538)\end{array}$ & $\begin{array}{c}0.700 \\
(0.622)\end{array}$ & $\begin{array}{c}0.742 \\
(0.659)\end{array}$ & $\begin{array}{c}0.967 \\
(0.949)\end{array}$ & $\begin{array}{c}0.767 \\
(0.701)\end{array}$ & $\begin{array}{c}0.507 \\
(0.481)\end{array}$ & $\begin{array}{c}0.861 \\
(0.806)\end{array}$ & $\begin{array}{c}0.550 \\
(0.512)\end{array}$ & 1 \\
\hline
\end{tabular}


By implementing the principles of AHP and the appropriate calculations, the relative importance between factors in BA 5 group is obtained (see the fourth column in Table 9). Consistency ratio in this case is $\mathrm{CR}_{\mathrm{GM}}=0.003111\left(\mathrm{CR}_{\mathrm{SSP}}=0.005330\right)$, which is satisfactory. The final results of comparison show that the factor Price has the highest impact in the business area - Business policy.

\subsection{Determining the importance of factors in the group Service management - BA 6}

The group BA 6 includes four factors. The comparison matrix of BA 6 group is shown in Table 8. By implementing the appropriate calculations, the results shown in Table 9 are obtained (the fourth column). Consistency ratio in this case is $\mathrm{CR}_{\mathrm{GM}}=0.006677\left(\mathrm{CR}_{\mathrm{SSP}}=\right.$ 0.013790), on the basis of which can be concluded that it is satisfactory. The final results of comparison show that the factor Security of postal items has the highest impact in the business area - Service management.

Table 8. Pairwise comparisons of factors in BA 6 group

\begin{tabular}{|c|c|c|c|c|}
\hline Factors & F8 GM(SSP) & F11 GM(SSP) & F12 GM(SSP) & F19 GM(SSP) \\
\hline F8 & 1 & $1.034(1.054)$ & $0.944(0.917)$ & $0.891(0.846)$ \\
\hline F11 & $0.967(0.948)$ & 1 & $0.717(0.624)$ & $1.059(1.091)$ \\
\hline F12 & $1.059(1.091)$ & $1.394(1.603)$ & 1 & $0.967(0.948)$ \\
\hline F19 & $1.122(1.182)$ & $0.944(0.917)$ & $1.034(1.054)$ & 1 \\
\hline
\end{tabular}

\subsection{Importance of influencing factors on business performance}

Results of the proposed A'BA model are shows in the Table 9. In addition to the importance of the groups (BA), the relative importance of each factor within the group (fourth column) is also shown. The values out of brackets represent the results obtained when a geometric mean (GM) approach is used for the aggregation of experts' assessments, while the values in brackets represent the results when the proposed concept in the paper is used for the aggregation of experts' assessments - Saaty's scale in the plane (SSP). The obtained values of importance in both cases are approximately equal, and the order of importance of elements (BA groups, factors within groups) is identical.

From the aspect of further analysis and performance improvement, it is important to pay attention at least to each of the most important factors in each of the groups. In this paper, only one factor is analysed in details. This factor is chosen in accordance with the methodology which is a way of expressing the relative importance of factors at global level and which can be found in the literature (Görener, 2012; Görener et al., 2012; Kil et al., 2016). The global importance of each factor was calculated by considering both the values of importance of the factor within the BA, and the importance of the BA to which it belonged (see the fifth column in Table 9). Here, it should be mentioned that the result of this method for calculation of the global importance of factors should be accepted conditionally. Namely, the approach is not entirely suitable for this purpose. There are corresponding disadvantages, which primarily relate to the fact that a particular factor belongs to one BA group and is not substantially 
important for other BA groups (globally). On the other hand, the experts determined the relative importance of groups among themselves, and because of this, however, there can be some connection between the relative and global importance of the factors belonging to a particular group. In addition, by applying this methodology, the factors from groups containing a smaller number of factors are favoured (since the total sum of the relative importance of the factors is 1). In order to eliminate this inconsistency, the application of a corrective factor expressed by Equation 2 is proposed. In this way, a normalization of assessments is done in accordance with the total number of factors and the number of factors in each of the groups.

$$
C_{i F_{a g}}=i F_{a g} \times \frac{n_{F g}}{N_{F}},
$$

where $C_{i F_{a g}}$ is the corrected value of importance of the factor $a$ from group $g ; i F_{a g}$ is the importance of the factor $a$ from group $g ; n_{F g}$ is the number of factors in group $g ; N_{F}$ is the total numbers of factors.

In this way, the corrected values of factor importance are obtained (the sixth column in Table 9), based on which the global importance is calculated (the seventh column in Table 9).

The obtained relationship between the factors by global importance (the fifth and seventh column in Table 9) in relation to all business areas is represented in Figure 4.

Table 9. Importance of factors

\begin{tabular}{|c|c|c|c|c|c|c|}
\hline BA & $\begin{array}{c}\text { Importance } \\
\text { of BA } \\
\text { GM(SSP) }\end{array}$ & Factors & $\begin{array}{l}\text { Importance } \\
\text { of factors } \\
\text { GM(SSP) }\end{array}$ & $\begin{array}{c}\text { Global } \\
\text { importance } \\
\text { of factors } \\
\text { GM(SSP) }\end{array}$ & $\begin{array}{c}\text { Corrected } \\
\text { importance } \\
\text { of factors } \\
\text { GM(SSP) }\end{array}$ & $\begin{array}{c}\text { Corrected } \\
\text { global } \\
\text { importance } \\
\text { of factors } \\
\text { GM(SSP) }\end{array}$ \\
\hline 1 & 2 & 3 & 4 & 5 & 5 & 6 \\
\hline \multirow{4}{*}{ BA1 } & \multirow{4}{*}{$\begin{array}{c}0.200963 \\
(0.216153)\end{array}$} & F6 & $\begin{array}{c}0.234289 \\
(0.229524)\end{array}$ & $\begin{array}{c}0.047083 \\
(0.049612)\end{array}$ & $\begin{array}{c}0.078096 \\
(0.076508)\end{array}$ & $\begin{array}{c}0.015694 \\
(0.016537)\end{array}$ \\
\hline & & F17 & $\begin{array}{c}0.275878 \\
(0.288021)\end{array}$ & $\begin{array}{c}0.055441 \\
(0.062257)\end{array}$ & $\begin{array}{c}0.091959 \\
(0.096007)\end{array}$ & $\begin{array}{c}0.018480 \\
(0.020752)\end{array}$ \\
\hline & & F29 & $\begin{array}{c}0.226424 \\
(0.216122)\end{array}$ & $\begin{array}{c}0.045503 \\
(0.046715)\end{array}$ & $\begin{array}{c}0.075475 \\
(0.072041)\end{array}$ & $\begin{array}{c}0.015168 \\
(0.015572)\end{array}$ \\
\hline & & F30 & $\begin{array}{c}0.263409 \\
(0.266333) \\
\end{array}$ & $\begin{array}{c}0.052935 \\
(0.057569) \\
\end{array}$ & $\begin{array}{c}0.087803 \\
(0.088778) \\
\end{array}$ & $\begin{array}{c}0.017645 \\
(0.019190) \\
\end{array}$ \\
\hline \multirow{3}{*}{ BA2 } & \multirow{3}{*}{$\begin{array}{c}0.195781 \\
(0.206533)\end{array}$} & F4 & $\begin{array}{c}0.244486 \\
(0.230862) \\
\end{array}$ & $\begin{array}{c}0.047866 \\
(0.047681) \\
\end{array}$ & $\begin{array}{c}0.061121 \\
(0.057716) \\
\end{array}$ & $\begin{array}{c}0.011966 \\
(0.011920) \\
\end{array}$ \\
\hline & & F9 & $\begin{array}{c}0.428096 \\
(0.448963) \\
\end{array}$ & $\begin{array}{c}0.083813 \\
(0.092726) \\
\end{array}$ & $\begin{array}{c}0.107024 \\
(0.112241) \\
\end{array}$ & $\begin{array}{c}0.020953 \\
(0.023181) \\
\end{array}$ \\
\hline & & F16 & $\begin{array}{c}0.327418 \\
(0.320175)\end{array}$ & $\begin{array}{c}0.064102 \\
(0.066127)\end{array}$ & $\begin{array}{c}0.081855 \\
(0.080044)\end{array}$ & $\begin{array}{c}0.016026 \\
(0.016532)\end{array}$ \\
\hline \multirow{3}{*}{ BA3 } & \multirow{3}{*}{$\begin{array}{c}0.163853 \\
(0.161047)\end{array}$} & F3 & $\begin{array}{c}0.259634 \\
(0.275203)\end{array}$ & $\begin{array}{c}0.042542 \\
(0.044321)\end{array}$ & $\begin{array}{c}0.108181 \\
(0.114668)\end{array}$ & $\begin{array}{c}0.017726 \\
(0.018467)\end{array}$ \\
\hline & & F5 & $\begin{array}{c}0.211712 \\
(0.216125)\end{array}$ & $\begin{array}{c}0.034690 \\
(0.034806)\end{array}$ & $\begin{array}{c}0.088213 \\
(0.090052)\end{array}$ & $\begin{array}{c}0.014454 \\
(0.014503)\end{array}$ \\
\hline & & F7 & $\begin{array}{c}0.198403 \\
(0.195828)\end{array}$ & $\begin{array}{c}0.032509 \\
(0.031537)\end{array}$ & $\begin{array}{c}0.082668 \\
(0.081595)\end{array}$ & $\begin{array}{c}0.013545 \\
(0.013141)\end{array}$ \\
\hline
\end{tabular}


End of Table 9

\begin{tabular}{|c|c|c|c|c|c|c|}
\hline 1 & 2 & 3 & 4 & 5 & 5 & 6 \\
\hline & & F14 & $\begin{array}{c}0.170869 \\
(0.163657) \\
\end{array}$ & $\begin{array}{c}0.027997 \\
(0.026356) \\
\end{array}$ & $\begin{array}{c}0.071196 \\
(0.068191) \\
\end{array}$ & $\begin{array}{c}0.011666 \\
(0.010982) \\
\end{array}$ \\
\hline & & F21 & $\begin{array}{c}0.159382 \\
(0.149187)\end{array}$ & $\begin{array}{c}0.026115 \\
(0.024026)\end{array}$ & $\begin{array}{c}0.066409 \\
(0.062161)\end{array}$ & $\begin{array}{c}0.010881 \\
(0.010011)\end{array}$ \\
\hline \multirow{3}{*}{ BA4 } & \multirow{3}{*}{$\begin{array}{c}0.136223 \\
(0.125103)\end{array}$} & F25 & $\begin{array}{c}0.343507 \\
(0.347549)\end{array}$ & $\begin{array}{c}0.046794 \\
(0.043479)\end{array}$ & $\begin{array}{c}0.085877 \\
(0.086887)\end{array}$ & $\begin{array}{c}0.011698 \\
(0.010870)\end{array}$ \\
\hline & & F26 & $\begin{array}{c}0.333231 \\
(0.333136)\end{array}$ & $\begin{array}{c}0.045394 \\
(0.041676)\end{array}$ & $\begin{array}{c}0.083308 \\
(0.083284)\end{array}$ & $\begin{array}{c}0.011348 \\
(0.010419)\end{array}$ \\
\hline & & F28 & $\begin{array}{c}0.323261 \\
(0.319315)\end{array}$ & $\begin{array}{c}0.044036 \\
(0.039947)\end{array}$ & $\begin{array}{c}0.080815 \\
(0.079829)\end{array}$ & $\begin{array}{c}0.011009 \\
(0.009987)\end{array}$ \\
\hline \multirow{12}{*}{ BA5 } & \multirow{12}{*}{$\begin{array}{c}0.147659 \\
(0.139116)\end{array}$} & $\mathrm{F} 1$ & $\begin{array}{c}0.105876 \\
(0.115974)\end{array}$ & $\begin{array}{c}0.015633 \\
(0.016134)\end{array}$ & $\begin{array}{c}0.105876 \\
(0.115974)\end{array}$ & $\begin{array}{c}0.015633 \\
(0.016134)\end{array}$ \\
\hline & & $\mathrm{F} 2$ & $\begin{array}{c}0.062292 \\
(0.055735)\end{array}$ & $\begin{array}{c}0.009198 \\
(0.007754)\end{array}$ & $\begin{array}{c}0.062292 \\
(0.055735)\end{array}$ & $\begin{array}{c}0.009198 \\
(0.007754)\end{array}$ \\
\hline & & F10 & $\begin{array}{c}0.090797 \\
(0.091467)\end{array}$ & $\begin{array}{c}0.013407 \\
(0.012725)\end{array}$ & $\begin{array}{c}0.090797 \\
(0.091467)\end{array}$ & $\begin{array}{c}0.013407 \\
(0.012725)\end{array}$ \\
\hline & & F13 & $\begin{array}{c}0.103771 \\
(0.110437)\end{array}$ & $\begin{array}{c}0.015323 \\
(0.015364)\end{array}$ & $\begin{array}{c}0.103771 \\
(0.110437)\end{array}$ & $\begin{array}{c}0.015323 \\
(0.015364)\end{array}$ \\
\hline & & F15 & $\begin{array}{c}0.092420 \\
(0.094751)\end{array}$ & $\begin{array}{c}0.013647 \\
(0.013181)\end{array}$ & $\begin{array}{c}0.092420 \\
(0.094751)\end{array}$ & $\begin{array}{c}0.013647 \\
(0.013181)\end{array}$ \\
\hline & & F18 & $\begin{array}{c}0.074720 \\
(0.071178)\end{array}$ & $\begin{array}{c}0.011033 \\
(0.009902)\end{array}$ & $\begin{array}{c}0.074720 \\
(0.071178)\end{array}$ & $\begin{array}{c}0.011033 \\
(0.009902)\end{array}$ \\
\hline & & F20 & $\begin{array}{c}0.068338 \\
(0.063295)\end{array}$ & $\begin{array}{c}0.010091 \\
(0.008805)\end{array}$ & $\begin{array}{c}0.068338 \\
(0.063295)\end{array}$ & $\begin{array}{c}0.010091 \\
(0.008805)\end{array}$ \\
\hline & & F22 & $\begin{array}{c}0.084879 \\
(0.083979)\end{array}$ & $\begin{array}{c}0.012533 \\
(0.011683)\end{array}$ & $\begin{array}{c}0.084879 \\
(0.083979)\end{array}$ & $\begin{array}{c}0.012533 \\
(0.011683)\end{array}$ \\
\hline & & F23 & $\begin{array}{c}0.099200 \\
(0.103904)\end{array}$ & $\begin{array}{c}0.014648 \\
(0.014455)\end{array}$ & $\begin{array}{c}0.099200 \\
(0.103904)\end{array}$ & $\begin{array}{c}0.014648 \\
(0.014455)\end{array}$ \\
\hline & & F24 & $\begin{array}{c}0.075710 \\
(0.072706)\end{array}$ & $\begin{array}{c}0.011179 \\
(0.010115)\end{array}$ & $\begin{array}{c}0.075710 \\
(0.072706)\end{array}$ & $\begin{array}{c}0.011179 \\
(0.010115)\end{array}$ \\
\hline & & F27 & $\begin{array}{c}0.084468 \\
(0.083841)\end{array}$ & $\begin{array}{c}0.012472 \\
(0.011664)\end{array}$ & $\begin{array}{c}0.084468 \\
(0.083841)\end{array}$ & $\begin{array}{c}0.012472 \\
(0.011664)\end{array}$ \\
\hline & & F31 & $\begin{array}{c}0.057530 \\
(0.052734)\end{array}$ & $\begin{array}{c}0.008495 \\
(0.007336)\end{array}$ & $\begin{array}{c}0.057530 \\
(0.052734)\end{array}$ & $\begin{array}{c}0.008495 \\
(0.007336)\end{array}$ \\
\hline \multirow{4}{*}{ BA6 } & \multirow{4}{*}{$\begin{array}{c}0.155520 \\
(0.152048)\end{array}$} & F8 & $\begin{array}{c}0.240112 \\
(0.235038)\end{array}$ & $\begin{array}{c}0.037342 \\
(0.035737)\end{array}$ & $\begin{array}{c}0.080037 \\
(0.078346)\end{array}$ & $\begin{array}{c}0.012447 \\
(0.011912)\end{array}$ \\
\hline & & F11 & $\begin{array}{c}0.231568 \\
(0.224412)\end{array}$ & $\begin{array}{c}0.036014 \\
(0.034121)\end{array}$ & $\begin{array}{c}0.077189 \\
(0.074804)\end{array}$ & $\begin{array}{c}0.012004 \\
(0.011374)\end{array}$ \\
\hline & & F12 & $\begin{array}{c}0.272916 \\
(0.282793)\end{array}$ & $\begin{array}{c}0.042444 \\
(0.042998)\end{array}$ & $\begin{array}{c}0.090972 \\
(0.094264)\end{array}$ & $\begin{array}{c}0.014148 \\
(0.014333)\end{array}$ \\
\hline & & F19 & $\begin{array}{c}0.255403 \\
(0.257757)\end{array}$ & $\begin{array}{c}0.039720 \\
(0.039192)\end{array}$ & $\begin{array}{c}0.085134 \\
(0.085919)\end{array}$ & $\begin{array}{c}0.013240 \\
(0.013064)\end{array}$ \\
\hline
\end{tabular}




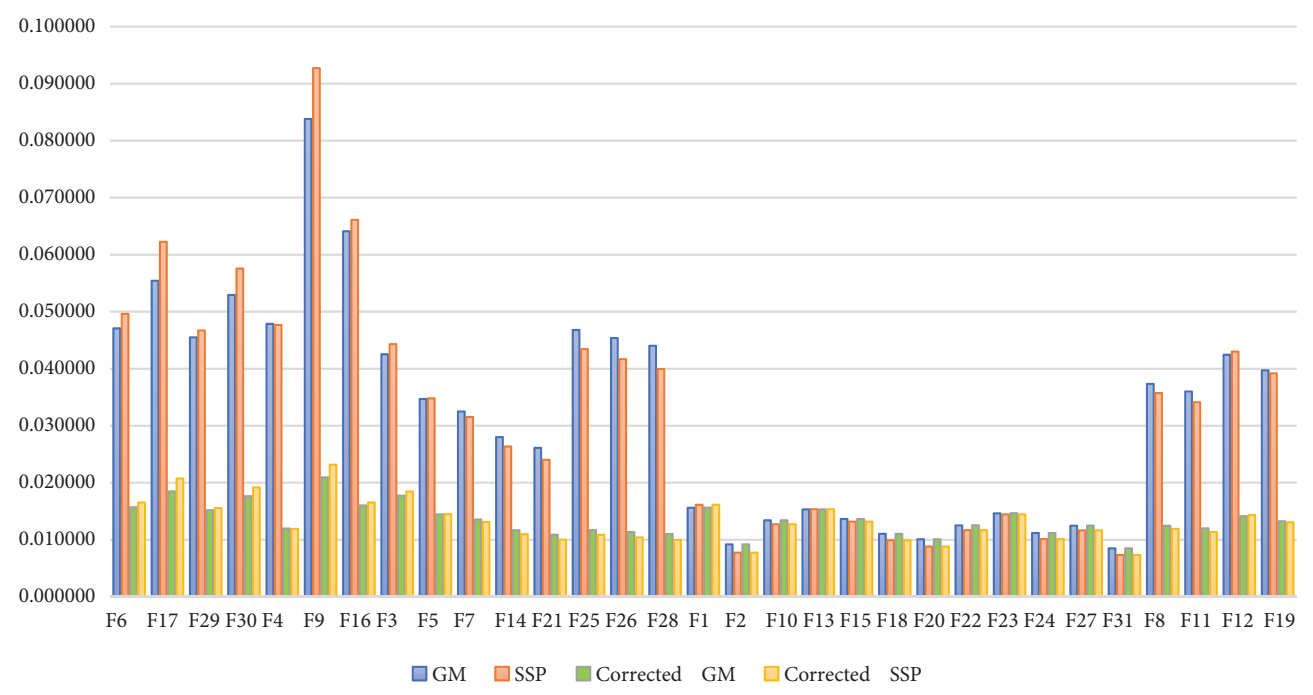

Figure 4. Relationship by global importance of the factors

The factor that has the greatest impact on the business performance in each of the applied approaches is F9 - Work-related attitudes and motivation of personnel. This factor belongs to the business area BA 2 - Human resource management. In accordance with the proposed model, this factor is analysed more detailed.

\subsection{Detailed analysis of the factor "Work-related attitudes and motivation of personnel"}

The next step in the model implies: a collection of expert opinions on approaches for detailed analysis of the factor "Work-related attitudes and motivation of personnel"; collecting expert opinions about the importance of the proposed approaches and based on the results a determination of adequate approach for the given problem; application of chosen approach and analysis. In accordance with the nature of the considered factor, in addition to already contacted twelve experts from the first part of the research, two experts from the field of organizational psychology working at the University of Belgrade and additional two experts from the Human resource department of the considered company were also contacted.

Based on the experts' opinions (16 experts in total), the following approaches could be implemented to analyse the observed factor:

A1. A survey of experts based on specialized questionnaires;

A2. A survey of employees based on specialized questionnaires;

A3. Benchmarking approach, which is based on a comparison with other companies;

A4. The research and comparison with other similar cases in the literature.

Further, experts have compared the proposed approaches, and the comparison matrix shown in Table 10 is obtained. Values outside brackets are aggregated using the geometric mean (GM) method, while the values in brackets are the result of aggregation using the concept proposed in this paper - Saaty's scale in the plane (SSP). 
Table 10. Pairwise comparisons of proposed approaches

\begin{tabular}{|c|c|c|c|c|}
\hline Approaches & A1 GM(SSP) & A2 GM(SSP) & A3 GM(SSP) & A4 GM(SSP) \\
\hline A1 & 1 & $0.667(0.604)$ & $0.639(0.569)$ & $1.707(1.844)$ \\
\hline A2 & $1.499(1.657)$ & 1 & $0.982(1.015)$ & $1.565(1.726)$ \\
\hline A3 & $1.565(1.759)$ & $1.018(0.985)$ & 1 & $1.177(1.323)$ \\
\hline A4 & $0.586(0.542)$ & $0.639(0.579)$ & $0.850(0.756)$ & 1 \\
\hline
\end{tabular}

The relative importance between approaches is shown in Table 11.

Table 11. The relative importance between approaches

\begin{tabular}{|l|c|c|c|c|}
\hline \multicolumn{1}{|c|}{ Approaches } & $\mathrm{A} 1 \mathrm{GM}(\mathrm{SSP})$ & $\mathrm{A} 2 \mathrm{GM}(\mathrm{SSP})$ & $\mathrm{A} 3 \mathrm{GM}(\mathrm{SSP})$ & $\mathrm{A} 4 \mathrm{GM}(\mathrm{SSP})$ \\
\hline Importance & 0.228278 & 0.298340 & 0.286732 & 0.186650 \\
degrees & $(0.218826)$ & $(0.311690)$ & $(0.297401)$ & $(0.172083)$ \\
\hline
\end{tabular}

Consistency ratio is $\mathrm{CR}_{\mathrm{GM}}=0.023587\left(\mathrm{CR}_{\mathrm{SSP}}=0.028840\right)$, representing a satisfactory value. This result indicates that the second proposed approach (A survey of employees based on specialized questionnaires) should be performed. Poor organizational commitment could be caused by many factors such as job dissatisfaction, motivation, bad leadership or organization policy (Dobrodolac et al., 2014). However, to further investigate this phenomenon, the examined psychologists in our study have recommended "The Organizational Commitment Questionnaire" to be used.

\subsubsection{Organizational Commitment Questionnaire}

The Organizational Commitment Questionnaire (OCQ) was developed by Porter and Smith (1970) in order to analyse the employee's commitment within in the organization. "The Organizational Commitment Questionnaire has been used successfully with high reliability in over thirty-five studies in organizational behavior" (Cullen et al., 1995). Various authors, such as Dubin et al. (1975), Mowday et al. (1974), Porter et al. (1976), used this questionnaire in their research, proving to be an appropriate for determining the organizational commitment.

The Organizational Commitment Questionnaire (Harold \& James, 1981) consists of the following 15 items:

1. I am willing to put in a great deal of effort beyond that normally expected in order to help this organization be successful;

2. I talk up this organization to my friends as a great organization to work for;

3. I feel very little loyalty to this organization;

4. I would accept almost any type of job assignment in order to keep working for this organization;

5. I find that my values and the organization's values are very similar;

6. I am proud to tell others that I am part of this organization;

7. I could just as well be working for a different organization as long as the type of work were similar; 
8. This organization really inspires the very best in me in the way of job performance;

9. It would take very little change in my present circumstances to cause me to leave this organization;

10. I am extremely glad that I chose this organization to work for, over others I was considering at the time I joined;

11. There's not too much to be gained by sticking with this organization indefinitely;

12. Often, I find it difficult to agree with this organization's policies on important matters relating to its employees;

13. I really care about the fate of this organization;

14. For me this is the best of all possible organizations for which to work;

15. Deciding to work for this organization was a definite mistake on my part.

The responses included - Strongly disagree; Moderately disagree; Slightly disagree; Neither disagree or agree; Slightly agree; Moderately agree; Strongly agree; scored 1 to 7 respectively.

\subsubsection{The results of survey and discussion}

The results of implemented Organizational Commitment Questionnaire describe the parameter "Work-related attitudes and motivation of personnel" in details. The survey was conducted at the postal company at the sample consisting of postal clerks (74), couriers (38), postmen (35), employees in the call centre (18), workers on manual processing of postal items (26) and employees working at managerial level (13). Postal clerks, postmen, couriers and employees in the call center have a direct contact with customers; therefore, customer quality assessment to a great extend depends on the way these workers meet customers' expectations. The workers on manual processing of mail significantly affect the performance of business process in many ways (security of items, errors in processing and routing, time limits, etc.). Finally, leaders are the most responsible for the performance of business process. The research was conducted in the postal company in Serbia. 204 employees were interviewed, out of which 160 responses were complete and relevant for analysis. Thus, the response rate was $78 \%$. The percentage distribution of responses is shown in Figure 5. It should be noted that the results are compatible with directions obtained by using the A'BA model. The questions $1,4,8$ and 12 will be further discussed because they can be considered as the most representative for describing the state and sources of the problem. Observing the question one, it can be noticed that $57.5 \%$ employees are not ready to make any additional effort to help the organization to be successful. This refers to the conclusion that majority of employees are not committed to the company and the alarming fact is that just $22.5 \%$ of them are dedicated. Some sort of explanation could be found in the question 8 , where $47.5 \%$ of the examinees stated the company did not inspire them in the best way for job performance. The reasons for this phenomenon should be examined further and they could be for example low salary, bad interpersonal communication, poor training and education programs and the lack of advancement opportunities. For example, research findings in the paper by Ismail et al. (2009) show a connection between the amount of earnings and job satisfaction. In addition, the study by Stare and Klun (2008) points out that investment in human resources and their training has a significant impact on the development of the public sector. When it comes to 


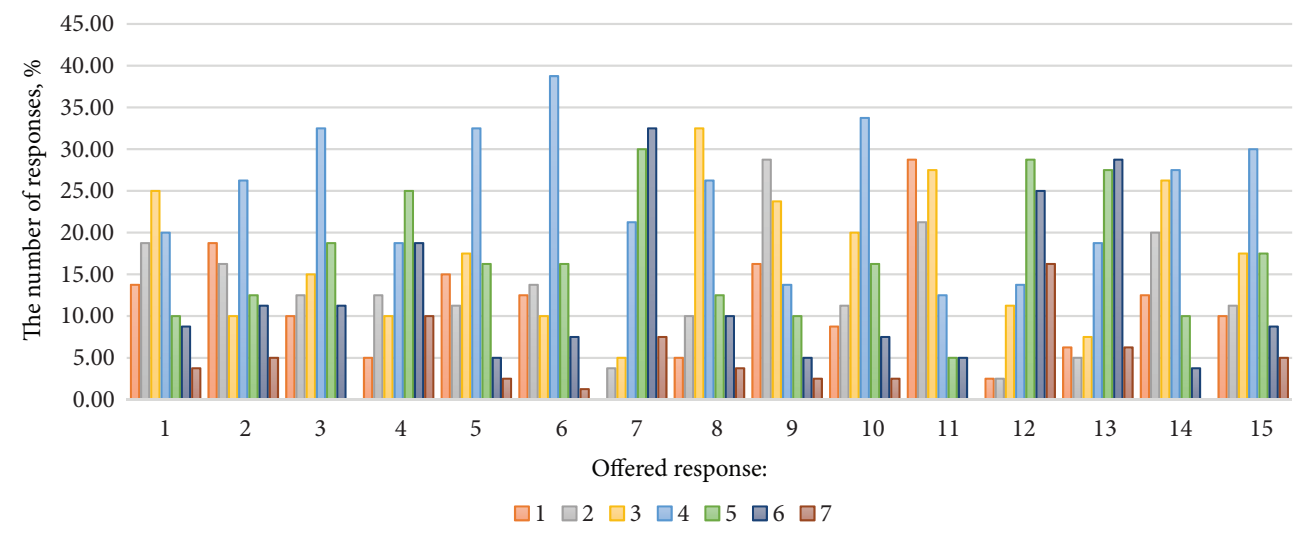

Figure 5. The results of survey

the process of qualification improvement of human resources, an additional problem arises in the case of public sector. Jasinskas et al. (2015) in their study showed that private organizations are more innovative in this field; applying modern methods which results in better achievements.

A related question is also the number 12 because it gives the information about employees' opinion on organization's policies. The fact that $70 \%$ of the examinees "find it difficult to agree with the organization's policies on important matters relating to its employees" is an important signal to the leaders that something should be changed. It is interesting to notice the question 4 because of its inconsistency with the previously described negative work-related attitudes. A majority of employees (53.75\%) "would accept almost any type of job assignment in order to keep working for the organization" which means that many of them feel they belong to the company. An explanation for this kind of answers might be found in a low economic activity in the considered society which results in difficulties when searching for another job.

\subsection{Proposal of activities to improve the business performance}

The proposed and applied model has enabled to define, in cooperation with experts from the considered field (postal services), a number of factors which affect the performance of business process in the postal company. In addition, a critical segment of the business process and influential factor which should be first improved is located. For a detailed analysis of the observed factor (Work-related attitudes and motivation of personnel), in accordance with its nature, it was necessary to include additional experts from the field of industrial and organizational psychology in the study. The expanded group of experts, proposed four approaches for a detailed analysis of the factor and made a final decision on the implementation of the second approach (A survey of employees based on specialized questionnaires). For the instrument within the approach, the experts from the fields of psychology, proposed "The Organizational Commitment Questionnaire". By analyzing the obtained results, certain activities which implementation could improve the business performance in the postal company are proposed. These activities, which are also formed in cooperation with an expanded 
group of experts, represent the ultimate goal of the proposed and applied model. In the concrete case, they are the following:

- Introduction of cash bonuses as rewards for achievements of employees;

- Investment in the equipment that is necessary for employees to perform the business;

- Strengthen the "collective spirit";

- Continuous education of employees;

- Raising awareness of employees about the importance of their work for the community and the economy of the country;

- Encouraging innovation among employees and use their experience in organizing the business process.

\section{Conclusions}

Each market-oriented distributive system continuously strives to improve a business performance. With this aim, the A'BA model, containing the main principles of the AHP analysis and theory of business areas, is proposed and applied. The proposed model implies a strategic approach, which enables the systematization of influencing factors on the performance of the business process, by business areas, ranking them by their importance. AHP method is used to determine the weight or importance of the business areas and factors. In this paper, a new concept for aggregation of experts' assessments named Saaty's Scale in the Plane - SSP was proposed. A comparative analysis of two methods of aggregation of the experts' assessments was performed. The first use the geometric mean - GM and the second the location of centroid - SSP method. The conclusion was that the obtained ranks of considered factors, as well as business areas, were identical.

The contributions of this paper can be classified into two general types:

- Methodological contribution: The strategic model for improving the performance of business process containing the A'BA model and a new concept for aggregation of experts' assessments - SSP are proposed. Furthermore, the applicability of the proposed new methodology is demonstrated in the case study, and the results of the new proposed concept SSP are compared with the well-known method of aggregation of the experts' assessments (geometric mean - GM);

- Practical contribution: The achieved benefits relate to the implementation of the proposed approaches in the case of a postal company, which is an unavoidable factor in the proper functioning of the business and state institutions, as well as for a normal life of citizens. Using the A'BA model, the opinions of eminent experts from the postal sector were sublimated and quantified, thus forming a strong basis for strategic management activities.

The benefits of the SSP concept are reflected primarily in the visualization of comparison results, which, in addition to easily recognizing the relationship of importance between the comparison elements, enables a simple sensitivity analysis. Namely, it is easy to analyse the impact of changing the position of the centroid on the final result of the comparison. The only limitation in applying this concept may be found in the fact that an analyst should possess the knowledge of computer-aided visualization techniques, that is, to be able to represent the results of comparisons in the plane based on the values of the experts' assessments and 
to determine the centroid of the corresponding surface. One of the directions of further research in this segment may be the creation of an application that will enable the SSP concept only based on the entered parameter values, which would eliminate the specified limitation.

The proposed A'BA model is used to locate the factor that has the highest impact on business performance improvement. In this case, it was the factor "Work-related attitudes and motivation of personnel". Accordingly, to get more specific information, the organizational commitment questionnaire was implemented. The research was carried out at the postal company. As mentioned in the Introduction section, the idea for creating such a model resulted from the similar concept combining AHP and SWOT (A'WOT method). The main advantage of the proposed A'BA, compared to A'WOT method, is the possibility of comparing higher number of groups which are related to the concrete business (there are always four groups of a general character compared in A'WOT). This means that BA groups are more specific and adjusted to the concrete company; therefore, the experts can assess the groups more objectively. The proposed model could be implemented in many other systems of distribution resulting in the following possibilities and benefits:

- Analyses of internal and external factors influencing the business performance;

- Analyses the existing state of the business performance;

- Analyses of the business areas in a system;

- Getting a relationship between the business areas/factors which influence the business process;

- Obtaining directions for business performance improvement;

- Forming a strong base for strategic planning.

The implementation of the model proposed in this paper can help leaders to design better plans, develop an adequate business strategy or focus their attention to the most important problem. Although the model does not take into account the financial component, it is clear that the improvement of business performance leads to the increased customer satisfaction and higher productivity. The proposed approach could be of interest to many companies, in particular for the systems of distribution, in the following way:

- The applicability of the proposed model is demonstrated in the case of distributive system, i.e. postal company;

- A possible approach for design of the business areas and influencing factors on business performance is given;

- The survey where the experts are interviewed is carried out and the assessment about influential factors on the business performance and their relative importance were obtained;

- The most important business area for postal service operator and further the most important factor are determined;

- A model for determining the most appropriate way for detailed analysis of the most important factor is proposed and implemented;

- The Organizational Commitment Questionnaire was implemented offering a valuable set of information about the problems and possible activities for business performance improvement in the postal company.

This model should be used in constant iterations, to cover all segments of the influential factors that need to be improved. In that way, the effects of previously committed changes 
can be tracked. In addition to the many advantages, there are some limitations of the A'BA model. The willingness of the experts to cooperate is certainly one of the key prerequisites for all models that involve their participation. In addition, in the implemented case, the pairwise comparisons were strictly numerical and the linguistic comparisons were not provided. To accommodate uncertainty in the decision-making process, the introduction of fuzzy approach would be welcome, allowing the experts more flexibility in comparisons. Also, the prioritization of experts is not included (correcting the impact of expert responses in accordance with relevant indicators, e.g. relative to the consistency of their responses), which would further contribute to the objectivity of the final results of comparison.

In accordance with the previously mentioned, the proposed methodology could be further expanded and tested. This may be seen as a direction for future research. Accordingly, the main activities for analysis and improvement of the proposed approach relates to:

- Modification of the proposed A'BA model in the form of application of various methods of multi-criteria analysis;

- Modification of the proposed A'BA model by introducing the application of Fuzzy AHP or neutrosophic AHP (N-AHP) approach instead of the standard AHP multi-criteria analysis;

- Introducing prioritization of experts in order to improve the objectivity of comparison results;

- Application of the proposed model in the same case as analysed in the paper, but in time-shifted iterations, in order to be able to conduct a comparative analysis;

- More detailed development of the proposed activities for improving the business performance;

- Testing the applicability of the proposed approach in different business systems.

\section{Author contributions}

Dragan Lazarević and Momčilo Dobrodolac designed the research methodology, performed the process of interviewing the experts and corresponding data processing. Libor Švadlenka made a research on the current knowledge in the considered topic. Bojan Stanivuković carried out the research by using the Organizational Commitment Questionnaire.

\section{Disclosure statement}

Authors declare that they do not have any competing financial, professional, or personal interests from other parties.

\section{References}

Abdel-Basset, M., Mohamed, M., \& Smarandache, F. (2018). An extension of neutrosophic AHP-SWOT analysis for strategic planning and decision-making. Symmetry, 10(4), 116. https://doi.org/10.3390/sym10040116

Aczél, J., \& Saaty, T. L. (1983). Procedures for synthesizing ratio judgements. Journal of Mathematical Psychology, 27(1), 93-102. https://doi.org/10.1016/0022-2496(83)90028-7 
Alkharabsheh, A., Moslem, S., \& Duleba, S. (2019). Evaluating passenger demand for development of the urban transport system by an AHP model with the real-world application of Amman. Applied Sciences, 9(22), 4759. https://doi.org/10.3390/app9224759

Borajee, M., \& Yakchali, S. H. (2011, July 2-3). Using the AHP-ELECTREIII integrated method in a competitive profile matrix. In International Conference on Financial Management and Economics (pp. 68-72), Hong Kong, China.

Bulgurcu, B., \& Nakiboglu, G. (2018). An extent analysis of 3PL provider selection criteria: A case on Turkey cement sector. Cogent Business \& Management, 5(1), 1469183.

https://doi.org/10.1080/23311975.2018.1469183

Cerlyawati, H., Anggoro, S., \& Zainuri, M. (2017). Environmental management of mangrove area in Northern coast, Central Java by using SWOT and AHP analysis. Advanced Science Letters, 23(3), 2501-2503. https://doi.org/10.1166/asl.2017.8656

Cho, Y. G., \& Cho, K. T. (2008). A loss function approach to group preference aggregation in the AHP. Computers \& Operations Research, 35(3), 884-892. https://doi.org/10.1016/j.cor.2006.04.008

Cullen, J., Johnson, J., \& Sakano, T. (1995). Japanese and local partner commitment to IJVs: psychological consequences of outcomes and investments in the IJV relationship (international joint ventures). Journal of International Business Studies, 26(1), 91-115. https://doi.org/10.1057/palgrave.jibs.8490167

Cyril, A., Mulangi, R. H., \& George, V. (2019). Performance optimization of public transport using integrated AHP-GP methodology. Urban Rail Transit, 5(2), 133-144. https://doi.org/10.1007/s40864-019-0103-2

Dobrodolac, M., Lazarevic, D., Svadlenka, L., \& Zivanovic, M. (2016). A study on the competitive strategy of the universal postal service provider. Technology Analysis \& Strategic Management, 28(8), 935-949. https://doi.org/10.1080/09537325.2016.1180357

Dobrodolac, M., Markovic, D., Cubranic-Dobrodolac, M., \& Denda, N. (2014). Using work stress measurement to develop and implement a TQM programme: A case of counter clerks in Serbian Post. Total Quality Management \& Business Excellence, 25(11-12), 1262-1279. https://doi.org/10.1080/14783363.2012.704280

Dubin, R., Champoux, J. E., \& Porter, L. W. (1975). Central life interests and organizational commitment of blue-collar and clerical workers. Administrative Science Quarterly, 20(3), 411-421. https://doi.org/10.2307/2392000

Etongo, D., Kanninen, M., Epule, T. E., \& Fobissie, K. (2018). Assessing the effectiveness of joint forest management in Southern Burkina Faso: A SWOT-AHP analysis. Forest Policy and Economics, 90, 31-38. https://doi.org/10.1016/j.forpol.2018.01.008

Forman, E. H. (1993). Facts and fictions about the analytic hierarchy process. Mathematical and Computer Modelling, 17(4-5), 19-26. https://doi.org/10.1016/0895-7177(93)90172-U

Forman, E., \& Peniwati, K. (1998). Aggregating individual judgments and priorities with the analytic hierarchy process. European Journal of Operational Research, 108(1), 165-169. https://doi.org/10.1016/S0377-2217(97)00244-0

Görener, A. (2012). Comparing AHP and ANP: An application of strategic decisions making in a manufacturing company. International Journal of Business and Social Science, 3(11), 194-208.

Görener, A., Toker, K., \& Uluçay, K. (2012, June 21-23). Application of combined SWOT and AHP: A case study for a manufacturing firm. In 8th International Strategic Management Conference, Barcelona, Spain.

Gottfried, O., De Clercq, D., Blair, E., Weng, X., \& Wang, C. (2018). SWOT-AHP-TOWS analysis of private investment behavior in the Chinese biogas sector. Journal of Cleaner Production, 184, 632-647. https://doi.org/10.1016/j.jclepro.2018.02.173 
Harold, L. A., \& James, L. P. (1981). An empirical assessment of organizational commitment and organizational effectiveness. Administrative Science Quarterly, 26(1), 1-14. https://doi.org/10.2307/2392596

Huang, Y. S., Liao, J. T., \& Lin, Z. L. (2009). A study on aggregation of group decisions. Systems Research and Behavioral Science: The Official Journal of the International Federation for Systems Research, 26(4), 445-454. https://doi.org/10.1002/sres.941

Ismail, A., Ibrahim, D. K. A., \& Girardi, A. (2009). The mediating effect of distributive justice in the relationship between pay design and job satisfaction. Proceedings of Rijeka Faculty of Economics: Journal of Economics and Business, 27(1), 129-148.

Jasinskas, E., Emeljanovas, A., \& Bilan, Y. (2015). Features of qualification improvement of human resources in public and private sector. Transformations in Business \& Economics, 14(2B), 462-480.

Jovčić, S., Průša, P., Dobrodolac, M., \& Švadlenka, L. (2019). A proposal for a decision-making tool in third-party logistics (3PL) provider selection based on multi-criteria analysis and the fuzzy approach. Sustainability, 11(15), 4236. https://doi.org/10.3390/su11154236

Kil, S. H., Lee, D., Kim, J. H., Li, M. H., \& Newman, G. (2016). Utilizing the analytic hierarchy process to establish weighted values for evaluating the stability of slope revegetation based on hydroseeding applications in South Korea. Sustainability, 8(1), 58. https://doi.org/10.3390/su8010058

Kim, J. H., Lee, C., \& Ahn, S. B. (2013). Analyzing the importance of reinforcement factors of competitiveness in Korea parcel service. Korea Logistics Review, 23(5), 31-49.

Kim, Y. J., \& Park, J. (2019). A sustainable development strategy for the Uzbekistan textile industry: The results of a SWOT-AHP analysis. Sustainability, 11(17), 4613. https://doi.org/10.3390/su11174613

Kişi, N. (2019). A strategic approach to sustainable tourism development using the A'WOT hybrid method: A case study of Zonguldak, Turkey. Sustainability, 11(4), 964. https://doi.org/10.3390/su11040964

Kotler, P. (1988). Marketing management: Analysis, planning, implementation, and control. Prentice-Hall International.

Liu, R., Wang, Y., \& Qian, Z. (2019). Hybrid SWOT-AHP analysis of strategic decisions of coastal tourism: A case study of Shandong Peninsula blue economic zone. Journal of Coastal Research, 94(sp1), 671-676. https://doi.org/10.2112/SI94-133.1

Mowday, R. T., Porter, L. W., \& Dubin, R. (1974). Unit performance, situational factors, and employee attitudes in spatially separated work units. Organizational Behavior and Human Performance, 12(2), 231-248. https://doi.org/10.1016/0030-5073(74)90048-8

Ossadnik, W., Schinke, S., \& Kaspar, R. H. (2016). Group aggregation techniques for analytic hierarchy process and analytic network process: a comparative analysis. Group Decision and Negotiation, 25(2), 421-457. https://doi.org/10.1007/s10726-015-9448-4

Porter, L. W., \& Smith, F. J. (1970). The etiology of organizational commitment (unpublished paper). University of California at Irvine.

Porter, L., Crampon, W, \& Smith, F. (1976). Organizational commitment and managerial turnovers: A longitudinal study. Organizational Behavior and Human Performance, 15(1), 87-98. https://doi.org/10.1016/0030-5073(76)90030-1

Saaty, T. L. (1977). A scaling method for priorities in hierarchical structures. Journal of Mathematical Psychology, 15(3), 234-281. https://doi.org/10.1016/0022-2496(77)90033-5

Saaty, T. L. (1989). Group decision making and the AHP. In The analytic hierarchy process (pp. 59-67). Springer, Berlin, Heidelberg. https://doi.org/10.1007/978-3-642-50244-6_4

Shahba, S., Arjmandi, R., Monavari, M., \& Ghodusi, J. (2017). Application of multi-attribute decisionmaking methods in SWOT analysis of mine waste management (case study: Sirjan's Golgohar iron mine, Iran). Resources Policy, 51, 67-76. https://doi.org/10.1016/j.resourpol.2016.11.002 
Singh, R. K., Gunasekaran, A., \& Kumar, P. (2018). Third party logistics (3PL) selection for cold chain management: a fuzzy AHP and fuzzy TOPSIS approach. Annals of Operations Research, 267(1-2), 531-553. https://doi.org/10.1007/s10479-017-2591-3

Solangi, Y. A., Tan, Q., Mirjat, N. H., \& Ali, S. (2019). Evaluating the strategies for sustainable energy planning in Pakistan: An integrated SWOT-AHP and Fuzzy-TOPSIS approach. Journal of Cleaner Production, 236, 117655. https://doi.org/10.1016/j.jclepro.2019.117655

Stare, J., \& Klun, M. (2008). Improving public administration performance demands investment in human resources. Proceedings of Rijeka Faculty of Economics: Journal of Economics and Business, 26(1), 151-173.

Teichmann, D., Dorda, M., \& Ivan, M. (2014, May 28-30). Multi-criteria optimization of distribution system structure - comparison of selected methods and their effectiveness. In XVII International Scientific Conference - Quantitative methods in Economics-Multiple Criteria Decision Making, Virt, Slovakia.

Toth, W., \& Vacik, H. (2018). A comprehensive uncertainty analysis of the analytic hierarchy process methodology applied in the context of environmental decision making. Journal of Multi-Criteria Decision Analysis, 25(5-6), 142-161. https://doi.org/10.1002/mcda.1648

Vieira, J. G. V., Toso, M. R., da Silva, J. E. A. R., \& Ribeiro, P. C. C. (2017). An AHP-based framework for logistics operations in distribution centres. International Journal of Production Economics, 187, 246-259. https://doi.org/10.1016/j.ijpe.2017.03.001

Wang, X. P., Zhang, J., \& Yang, T. (2014). Hybrid SWOT approach for strategic planning and formulation in China worldwide express mail service. Journal of Applied Research and Technology, 12, 230-238. https://doi.org/10.1016/S1665-6423(14)72339-9

Wang, Y. J., Han, T. C., \& Chou, M. T. (2016). Applying fuzzy AHP in selection of transport modes for Kinmen military logistics. Journal of Marine Science and Technology, 24(2), 222-232.

Wheelen, T. L., \& Hunger, J. D. (1995). Strategic management and business policy. Addison Wesley, Reading, MA. 